\title{
Eco-friendly coloration of linen to ameliorate its practical approach
}

\author{
Md. Nahid Pervez ${ }^{1,2}$, Umarsharif Y. Inamdar ${ }^{1}$, Md. Eman Talukder ${ }^{1}$, Sakil Mahmud ${ }^{1}$, Md. Ahsan Habib ${ }^{1}$, Md. Kamruzzaman $^{1}$ \\ and Yingjie $\mathrm{Cai}^{3,4}$ \\ ${ }^{1}$ School of Chemistry and Chemical Engineering, Wuhan Textile University, Wuhan 430073, China \\ ${ }^{2}$ Research institute of flexible materials, School of Textiles \& Design, Heriot-Watt University, Galashiels TD1 3HF, UK \\ ${ }^{3}$ Hubei Provincial Engineering Laboratory for Clean Production and High Value Utilization of Bio-based Textile Materials, Wuhan Textile \\ University, Wuhan 430073, China \\ ${ }^{4}$ Engineering Research Centre for Clean Production of Textile Dyeing and Printing, Ministry of Education, Wuhan Textile University, Wuhan, \\ 430073, China
}

\begin{abstract}
Reactive dyes are the perfect choice for dyeing of cellulosic fibers due to produce a wide gamut of bright colors with excellent color fastness, however environmental pollution is increasing in recent days seeing that of making use of inorganic salt and alkali. This paper offers a new avenue for eco-friendly dyeing of linen fiber by incorporating biodegradable alkaline organic salts in presence of three commercial reactive dyes and amongst them organic salt i.e. disodium maleate showed superior result in terms of color strength (K/S), dye exhaustion (\%), color fastness, tensile strength and crease recovery angle parameters that were evaluated by traditional technique.
\end{abstract}

\section{Introduction}

The eco-friendly fabric dyeing has received more and more interest due to the elevated recognition of environmental pollution likes discharge of nonbiodegradable inorganic salts, alkalis, different processing aids and organic subject similar to dyes to the effluent for the duration of the arena [1]. The foremost assignment that now faces the cloth industry is to change creation at a competitive price by means of utilizing secure dyes and chemical substances as good as via decreasing treatment fee [2]. Reactive dyes are one of the lots of accepted classes of dye stuffs. They can fix to fabric by the accumulation of a covalent bond and accordingly accept boundless photolytic adherence and affable wash fastness on textile fibers, which is an advantage over added classes of dyes, such as direct dyes that are immobilized via physical adsorption or mechanical entrapment (1) Reactive dyes with the dichlorotriazine reactive group accumulation are frequently acclimated in the dyeing of affection fabrics (2) Dye fixation involves the formation of a covalent bond between a hydroxyl group, beneath alkaline altitude in the fabric, and the dye molecule, by the nucleophilic displacement of chloride ion $[3,4]$. The inorganic salt, similar to sodium chloride or sodium sulphate, for dye transfer to and penetration into the fibre, and inorganic alkali, reminiscent of sodium bicarbonate, sodium carbonate or sodium hydroxide, for dye-fibre reaction, are required in significant portions to achieve the dyeing system. Without reference to the dyeing approach utilizing reactive dyes, nearly the entire salt and alkali is drained to effluent. Such effluents are characterised through high phases of dissolved solids which is environmentally undesirable $[5,6]$. In up to date years, alternative of nonbiodegradable inorganic salt with biodegradable natural and organic salt is attracting the concentration of many researchers in this area. It is pronounced that inorganic salts will also be efficaciously replaced by using the organic salt in the textile process with larger dye uptake than sodium chloride in the reactive dyeing system [7]. Linen may be the oldest fabric known, is an important textile material with different characteristics. With the trend of appearance appear natural, comfortable yet elegant fabrics, linen and linenblended fabrics accept acquired authority and added in acceptability attributable to the fabric qualities of comfort, hygiene, and elegance recently. Linen reduces $\gamma$-radiation nearly by bisected and protects the human organism towards sun radiation. It is an array of nice actual for advantageous applications due to its amore transfer, permeability to air. Heat conductivity of linen is five times as high as that of wool and 19 times as that of silk, additionally, the tensile strength of linen thread is twice as high as that of cotton and three times that of wool. Nevertheless, dyeability is the main barrier that unable its wide applications in the real life [8]. Therefore, development of fiber modification and finishing treatments are required to improve the performance of linen fabric to promote its production as well as its usage.

Present research aims to establish a platform for ecofriendly dyeing of linen in presence of biodegradable salts as exhausting agents in order to reduce the discharge pollution of wastewater. To the best knowledge of authors up to date no directly related research has been reported. 


\section{Experimental}

\subsection{Materials}

Plain, woven, bleached, and scoured linen fabric (210 $\mathrm{g} / \mathrm{m}^{2}$ ) was used throughout this work. The main dyes used for this study were C.I. Reactive Yellow 176 (Dye 1), C.I. Reactive Yellow 3 (Dye 2), and C.I. Reactive Blue 19 (Dye 3). Sodium chloride, sodium carbonate, sodium sulfate, sodium citrate, sodium edate, sodium oxalate and disodium maleate were analytical of commercial grade and used without further purification.

\subsection{Dyeing procedures}

All dyeing processes were carried out using a liquor ratio of $30: 1$. The dyebath was prepared by adding the three dyes ( $1 \%$ o.w.f.) to distilled water at $60^{\circ} \mathrm{C}$ and wet fabric and left for $15 \mathrm{~min}$, then The temperature was raised subsequently to $80^{\circ} \mathrm{C}$, and fixation was conducted using sodium carbonate and left for $30 \mathrm{~min}$. The dyed fabrics were rinsed thoroughly in hot water and soaped in a soap solution $5 \mathrm{~min}$ at $90^{\circ} \mathrm{C}$, and then rinsed thoroughly in hot tap water and air-dried.

\subsection{Measurements}

The color strength $(K / S)$ and fastness values were determined according to our previous work [9]. The dye exhaustion percentage of samples $(\mathrm{E} \%)$ was calculated according to the following equation:

$$
\mathrm{E} \%=100 \% \times\left(\mathrm{C}_{1}-\mathrm{C}_{2}\right) / \mathrm{C}_{1}
$$

Where $C_{1}$ and $C_{2}$ are the concentrations of dye in the dyebath before and after dyeing, respectively. Tensile strength of fabric was measured by following ASTM-D5035(1995) method using Instron tensile tester (Model No. 5565) [10]. The standard ASTM D 1269 test method was used to determine the crease recovery angle (CRA) using the Shirley Crease Recovery tester.

\section{Results and discussion}

\subsection{Color strength}

Different electrolytes and three reactive dyes with the same mass concentration $(30 \mathrm{~g} / \mathrm{L})$ were used for padsteam dyeing of linen fabric with $1 \%$ shade, in order to get the suitable biodegradable salt for eco-friendly dyeing of linen fibers is shown in Figure 1.

Salt is used for increasing dye levelness in the course of the fibre and the consequent colour-yield, in pad-steam dyeing. The response between the reactive dye molecules and the hydroxyl organizations of cellulose occur at alkaline $\mathrm{pH}$ conditions. The dye can also react with the hydroxide ions in an aqueous dye resolution $[11,12]$. Figure 1 shows the comparative color strength of the three dyed fabrics amongst these bought using sodium chloride, sodium sulfate, sodium citrate, sodium edate, sodium oxalate and disodium maleate. It was once clear that sodium citrate, sodium edate, sodium oxalate and disodium maleate considered as suitable electrolytes to interchange inorganic salts. Among the three dyed samples utilizing organic salts, sodium maleate showed the absolute best $\mathrm{K} / \mathrm{S}$ value on dye 3 sample. The major influence of the electrolytes on the dyes, moreover to its extinguishing outcomes on the negative charge on cellulose fibers, is to increase the aggregation of the dye molecules in solution via the common ion effectiveness. The electrolyte reduces the solubility of dye in the dyebath and modifies the equilibrium in desire of action of dye molecules from the approach to the fiber via suppressing the ionization of the dye molecule in solution. This is highly massive broaden comparing to the feasible shrink color-yield within the typical reactive dyeing of cellulose by pad-steam system for the reason that of immoderate dye hydrolysis and cut back ultimate dyefixation levels [13]. This may be attributed to the higher ionic-force and better stability (at elevated $\mathrm{pH}$ ) of disodium maleate for reaction between vinylsulphone derivatives (dye three) and cellulose. It indicated that as far as the $\mathrm{K} / \mathrm{S}$ value of the dyed samples had been concerned; disodium maleate might be a compatible substitution for inorganic salts worth one more is taught.

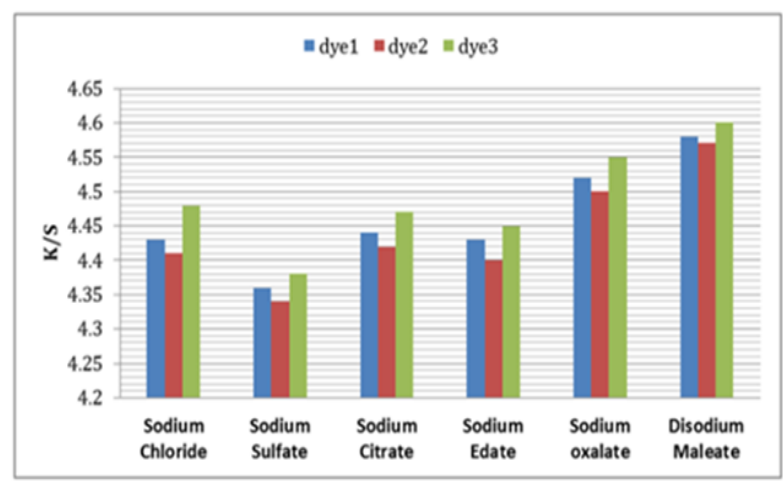

Figure 1. Effect of Different Electrolytes on Color Strength.

\subsection{Color Fastness}

As proven in Table 1, color fastness results that indicate that all the organic and inorganic salts dealt with fabrics have applicable color fastness results. The organic salts materials exhibit reasonably better color fastness results than the inorganic salts handled fabrics because of dyemordant complex may be firmly connected to the substrate ensuing into a greater color yield and low awareness of alkali, the extent of formation of nucleophilic cellulose $\mathrm{O}^{-}$moiety of the fabric is low, this ends up with low measure of nucleophilic addition reaction with the vinyl sulphone reactive dye. Furthermore, the fastness properties improved due to presence of benzene ring and conjugated system in the colorant [14]. Overall results confirmed that disodium maleate salt has exhibit satisfactory result after dyeing with vinyl sulphone based (dye 3).

\subsection{Dye exhaustion}

As shown in Figure 2, the exhaustion percent (E \%) effectivity of dyed materials is plotted in y-axis. For the 
same color percent of dye, three dyes deviate in dye absorb with fiber. The effect suggests that dye 1 and dye 3 at all times had a greater and just about identical percent of exhaustion. But dye 2 had a negative exhaustion percentage in evaluation with the others. It is visible that outcome of organic salts is superior on inorganic salts efficiency and disodium maleate as organic salt has been showed absolute best exhaustion rate amongst all dealt with samples in this study. As we know cellulose consists of a negative charge in pure water and dye is also anion consequently negatively charged, there's electrostatic anion-anion repulsion between dye and cellulose.

As a consequence, by including electrolyte to the dyebath, electrostatic barrier as appeared and often called the Donnan potential, can be mostly suppressed, facilitating dye/fabric contact and allowing better interaction of the Yoshida and van der Waal, forces and as a consequence making improvements to substantivity. The diffusion coefficient of the dye is as a consequence a function of each dye and electrolyte concentration [15]. The extent to which reactive dyes are littered with the addition of electrolytes to the dyebath is often called salt sensitivity. It is viewed that the initial rapid rise is due to the response of dye to the reducing of electrical potential barrier to diffusion as the concentration of electrolyte raises. Their hydrogen bonding ability can also be aided through their rectangular and flat molecular structure which allows for them to lie alongside a cellulose chain in register with hydroxyl corporations. Some studies proven salt free dyeing of cellulose material using cationization of the fabric itself in order that the dye will likely be migrated to the fabric and constant with none addition of salt to the dyeing tub [16-18]. However, majority of the chemical substances used for introducing cationic sites in cellulose material are themselves now not secure for the environment [19]. As a consequence, this record tried to compensate the alternate-off via utilizing decrease quantity of salt with higher dye fiber fixation and slash environmental have an effect on with the aid of utilizing biodegradable salt.

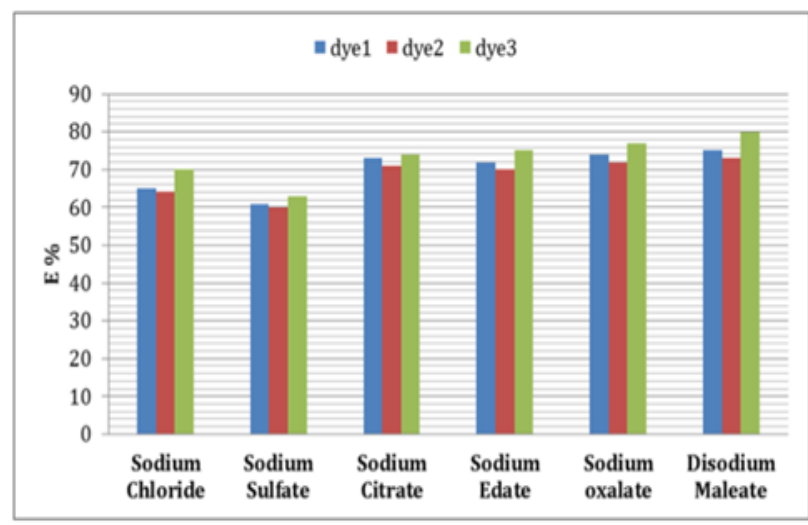

Figure 2. Effect of Different Electrolytes on Dye Exhaustion.

\subsection{Tensile strength}

Figure 3 shows the tensile strength values of three reactive situated dyed fabrics with inorganic and organic salts. It can be visible that the tensile strength of organic salts dealt with material suggests comparatively better than inorganic salts dealt with. On this case also disodium maleate salt carried out good those others with dye 3 . The feasible rationale for increase in tensile strength is the alkaline $\mathrm{pH}$ of disodium maleate, which can provide force to fabric and the network structure and excellent adhesion on the interface was liable for high tensile strength [20].

Table 1. Color Fastness Properties of Dyed Samples.

\begin{tabular}{|c|c|c|c|c|c|c|}
\hline \multirow{2}{*}{ Dyes } & \multirow{2}{*}{$\begin{array}{l}\text { Different } \\
\text { salts }\end{array}$} & \multicolumn{2}{|c|}{$\begin{array}{l}\text { Rubbing } \\
\text { fastness }\end{array}$} & \multicolumn{2}{|c|}{ Washing fastness } & \multirow{2}{*}{$\begin{array}{l}\text { Light } \\
\text { fastness }\end{array}$} \\
\hline & & Dry & Wet & $\begin{array}{l}\text { Color } \\
\text { change }\end{array}$ & Staining & \\
\hline \multirow{6}{*}{$\begin{array}{c}\text { Dye } \\
1\end{array}$} & $\begin{array}{l}\text { Sodium } \\
\text { chloride }\end{array}$ & $3-4$ & 3 & $3-4$ & 2 & 5 \\
\hline & $\begin{array}{l}\text { Sodium } \\
\text { sulfate }\end{array}$ & $3-4$ & 3 & $3-4$ & 2 & 4 \\
\hline & $\begin{array}{l}\text { Sodium } \\
\text { citrate }\end{array}$ & 4 & $3-4$ & 4 & 3 & 6 \\
\hline & $\begin{array}{l}\text { Sodium } \\
\text { edate }\end{array}$ & $4-5$ & $3-4$ & 4 & 3 & 6 \\
\hline & $\begin{array}{l}\text { Sodium } \\
\text { oxalate }\end{array}$ & $4-5$ & $3-4$ & 4 & $3-4$ & 6 \\
\hline & $\begin{array}{c}\text { Disodium } \\
\text { maleate }\end{array}$ & 5 & 4 & 5 & 4 & 7 \\
\hline \multirow{6}{*}{$\begin{array}{c}\text { Dye } \\
2\end{array}$} & $\begin{array}{l}\text { Sodium } \\
\text { chloride }\end{array}$ & 3 & 3 & 3 & 3 & 5 \\
\hline & $\begin{array}{l}\begin{array}{l}\text { Sodium } \\
\text { sulfate }\end{array} \\
\end{array}$ & 3 & 3 & 3 & 2 & 4 \\
\hline & $\begin{array}{l}\text { Sodium } \\
\text { citrate }\end{array}$ & 4 & $3-4$ & 4 & $3-4$ & 5 \\
\hline & $\begin{array}{l}\text { Sodium } \\
\text { edate }\end{array}$ & $4-5$ & 4 & 4 & $3-4$ & 6 \\
\hline & $\begin{array}{l}\begin{array}{l}\text { Sodium } \\
\text { oxalate }\end{array} \\
\end{array}$ & 4 & 4 & $4-5$ & $3-4$ & 6 \\
\hline & $\begin{array}{l}\text { Disodium } \\
\text { maleate }\end{array}$ & 5 & 4 & $4-5$ & 4 & 6 \\
\hline \multirow{6}{*}{$\begin{array}{c}\text { Dye } \\
3\end{array}$} & $\begin{array}{l}\text { Sodium } \\
\text { chloride }\end{array}$ & $3-4$ & $3-4$ & 3 & 3 & 6 \\
\hline & $\begin{array}{l}\begin{array}{l}\text { Sodium } \\
\text { sulfate }\end{array} \\
\end{array}$ & 3 & 3 & $3-4$ & 3 & 5 \\
\hline & $\begin{array}{l}\text { Sodium } \\
\text { citrate }\end{array}$ & 4 & 4 & 4 & 4 & 6 \\
\hline & $\begin{array}{c}\text { Sodium } \\
\text { edate }\end{array}$ & $4-5$ & 4 & $4-5$ & 4 & 6 \\
\hline & $\begin{array}{l}\begin{array}{l}\text { Sodium } \\
\text { oxalate }\end{array} \\
\end{array}$ & 5 & 4 & $4-5$ & $4-5$ & 6 \\
\hline & $\begin{array}{l}\text { Disodium } \\
\text { maleate }\end{array}$ & 5 & $4-5$ & 5 & $4-5$ & 7 \\
\hline
\end{tabular}

\subsection{Crease recovery angle}

Crease or creasing recovery is defined as the property of a fabric that enables it to balance from folding deformations. The most accepted adjustment of measuring crease recovery is to bend a strip of fabric by a folding force, advance it in the angled agreement for a accustomed period of time, and then measure the angle of recovery after the bending load is removed [21]. The higher the wrinkle recovery angle of a fabric, the better is its crease resistance. For automated applications, it has to be ensured that the biodegradable salts are not alone assuredly able in dyeing but as well they are accordant with the finishing agent. Consequently, the effects of 
adding the organic salts to the formulation of the crease resist finishes as well as the finish durability were evaluated. There are two theories for the apparatus of anti-wrinkle finishing of fabrics. The deposition theory proposes that small particles of finishing agents are dispersed in amorphous region of the fibres where they might be deposited after resinification and form $\mathrm{H}$-bonds with the fibre molecules. This may bind the movement of the atomic chains and abatement anamorphosis of the fabrics. The cross-linking approach proposes that finishing agents form covalent bonds with fibre molecules, and affix the adjoining atomic chains within the fibres. This gives the recoverability accessory of the deformed fibres and increases the wrinkle resistance. Also, as can be observed from Figure 4, disodium maleate treated fabric showed extensive wrinkle resistant value with dye 3 . This advance was mainly attributed to the actuality that the reactive dye could acknowledge with cellulose fibres through their H-bonds, which led to the cross-linking of cellulosic fibres and bound the about movement of the atomic chains [22]. It was found that both aforementioned theories are adaptable for the wrinkle resistant properties of dyed treated linen fabrics.

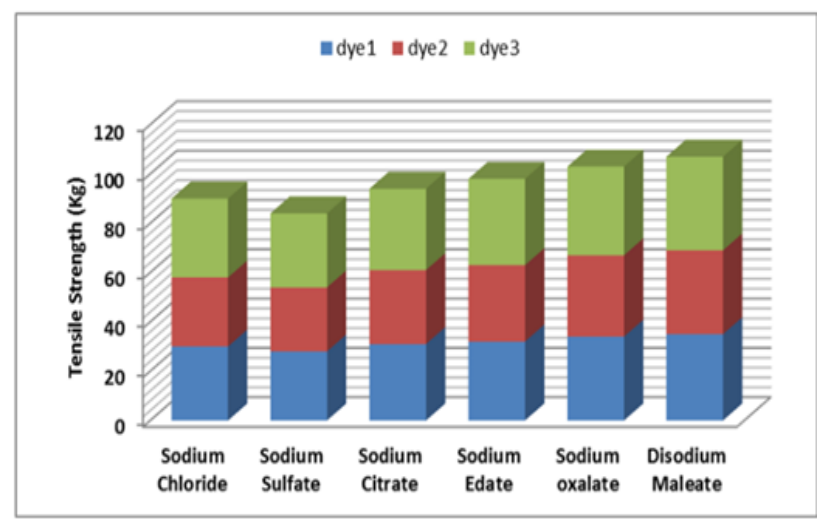

Figure 3. Effect of Different Electrolytes on Tensile Strength

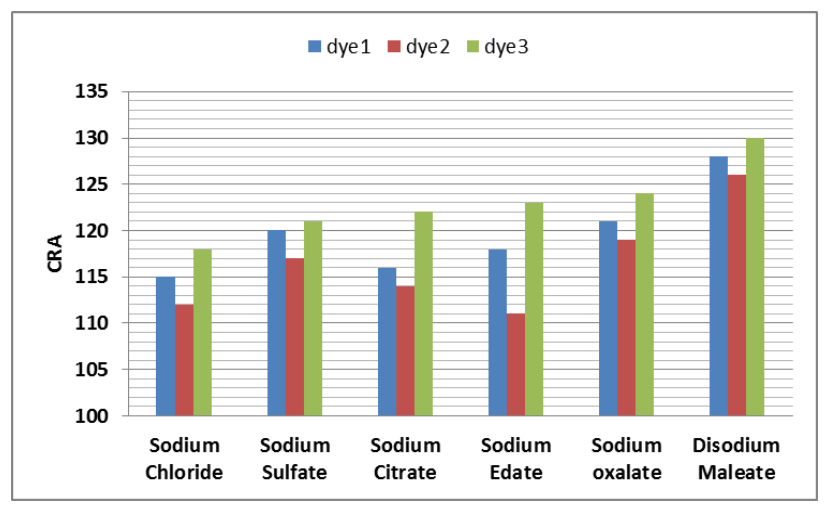

Figure 4. Effect of Different Electrolytes on crease recovery angle

\section{Conclusion}

This is the first report about disodium maleate used as biodegradable organic salt on linen by pad steam dyeing with reactive dyes. On the basis of the results given above, it can be concluded that in phrases of color strength, exhaustion (\%), color fastness, tensile strength and crease recovery angle, organic salts are inferior to inorganic salts and it explores the viability of exchanging the traditional inorganic salts through incorporating biodegradable organic salts.

\section{Acknowledgement}

This work was financially supported by the China National Textile \& Apparel Council (2013 "Textile Vision" Applied Basic Research, 2013-153); Hubei Province Science and Technology Support Program (Grant No. 2013BAA043) and the Collaborative Innovation Plan of Hubei Province for Key Technology of Eco-Ramie Industry (2014-8).

\section{References}

1. R. Chavan, IJFTR. 26, 93 (2001)

2. N. Ul-Haq, H. Nasir, J. Text. I. 103, 304 (2012)

3. N. Meksi, M.B. Ticha, M. Kechida, M.F. Mhenni, J. Clean. Prod. 24, 149 (2012)

4. T. K. Yip, E. R. Smith, J. Booth, R. G. Compton, C. M. Brennan, J. H. Atherton. J. of coll. and int. Sci. 186, 387 (1997)

5. P.J. Dolby, Textile Chemist \& Colorist. 9, 264 (1977)

6. J. Aspland, Textile Chemist \& Colorist. 24, 35 (1992)

7. H.G. Prabu, Color. Technol. 118, 131 (2002)

8. A. Hadj Taieb, S. Msahli, F. Sakli, J. Nat. Fibers. 7, $251(2010)$

9. M.N. Pervez, M.A. Rahman, IJSER. 6, 660 (2015)

10. A. Khan, M.N. Pervez, I.A. Khan, S. Ahmad, R. Masood, T. Hussain, F. Telegin, Asian J. Chem. 28, 1191 (2016)

11. D. Phillips, Advances in Colour Science and Technology. 1, 1 (1998)

12. J. Shore, Cellulosics dyeing. (1995).

13. A.D. Broadbent, Basic principles of textile coloration. (2001)

14. T. Gulzar, S. Adeel, I. Hanif, F. Rehman, R. Hanif, M. Zuber, N. Akhtar, J. Nat. Fibers. 12, 494 (2015)

15. A. Johnson, The theory of coloration of textiles. (1989)

16. K. Srikulkit, P. Santifuengkul, Color. Technol. 116, 398 (2000)

17. D. Chattopadhyay, IJFTR. 26, 108 (2001)

18. Y. Zhang, B. Zhang, Dyeing and Finishing. 8, 47 (2001)

19. S. Giolando, R. Rapaport, R. Larson, T. Federle, M. Stalmans, P. Masscheleyn, Chemosphere. 30, 1067 (1995)

20. C. Thongpin, J. Srimuk, P. Wachirapong. IOP Conference Series: Materials Science and Engineering. 87, (2015)

21. A. Sevda, E. Y1lmaz. Fibers and Polymers 17, 644 (2016)

22. H. Emadaldin, S. Shahidi, P. Zolgharnein. A. Res. J. 15104 (2015) 